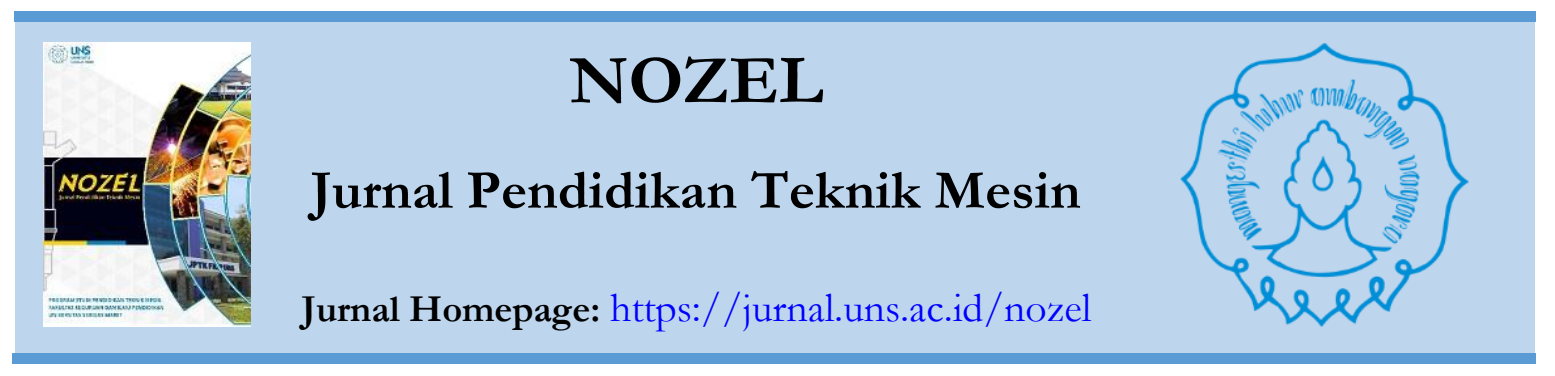

\title{
PENGARUH KUAT ARUS PADA PENGELASAN PADUAN ALUMINIUM 6061 DENGAN MENGGUNAKAN METODE LAS TIG TERHADAP KEKERASAN DAN STRUKTUR MIKRO
}

\author{
Rochim Toat Wicaksono ${ }^{1}$, Suharno ${ }^{1}$, Budi Harjanto ${ }^{1}$ \\ ${ }^{1}$ Program Studi Pendidikan Teknik Mesin, FKIP, Universitas Sebelas Maret Surakarta \\ e-mail: rochim.toat37@gmail.com
}

\begin{abstract}
The objective of research was to find out the effect of current on microstructure and hardness value in Aluminium Alloy 6061 before (raw material) and after welding using Tungsten Inert Gas (TIG) welding method with filler rod ER4043. This research uses experiment methods. Technique of analyzing data used was a descriptive comparative research. The instruments used for testing microstructure and hardness were Olympus Metallurgical Microscope and Vikers Hardness Tester. Base on the result of research, it could be concluded that the result of microstructure testing showed the reduced $\mathrm{Mg}_{2} \mathrm{Si}$ phase width after welding. In raw material, the $\mathrm{Mg}_{2}$ Si phase seemed to diffuse surrounding the $\alpha$-Al phase surface, but the result of welding using TIG welding method with current of $100 \mathrm{~A}, 110 \mathrm{~A}$, and $115 \mathrm{~A}$ showed that $\mathrm{Mg} \mathrm{g}_{2}$ Si phase reduced in each specimen, so that $\alpha-\mathrm{Al}$ phase was very dominant. The hardness value of hardness result showed the different hardness level. The specimen with current of 110A had higher hardness level of 65.4 VHN than the specimen with current of $100 \mathrm{~A}(55.7 \mathrm{VHN})$ and $115 \mathrm{~A}(55.9 \mathrm{VHN})$. The result of hardness testing on raw material was 120.4 VHN. This research showed that the welding using varying current changed microstructure and affected the hardness value of Aluminum Alloy 6061.
\end{abstract}

Keywords: Tungsten Inert Gas (TIG) welding, Aluminum Alloy 6061, microstructure, hardness

\section{A. PENDAhuluan}

$$
\text { Aluminium Alloy (AA) } 6061
$$

merupakan paduan Aluminium yang umumnya diaplikasikan untuk automotif maupun alat-alat konstruksi. Pada perancangan konstruksi menggunakan material paduan Aluminium 6061, banyak melibatkan unsur pengelasan dengan sambungan las sebagai alternatif untuk menyambung bagian-bagian tertentu. Pembuatan sambungan las secara teknis memerlukan keterampilan yang tinggi bagi pengelasnya agar diperoleh sambungan dengan kualitas baik. Salah satu sambungan las cacat lambat laun akan menimbulkan rusaknya sambungan yang 
lain dan akhirnya konstruksi dapat runtuh yang menyebabkan kerugian materi yang tidak sedikit bahkan juga korban jiwa. Kualitas pengelasan yang baik tentunya juga digunakan suatu metode pengelasan yang sesuai. Salah satunya adalah metode pengelasan TIG. Pengelasan TIG dipilih karena hasil pengelasan tersebut lebih bersih, kuat, dan di samping itu dapat digunakan pada material non ferro seperti Aluminium ( $\mathrm{Al})$.

Pemakaian arus yang sesuai merupakan salah satu parameter dalam proses pengelasan. Untuk mengetahui pengaruh variasi kuat arus terhadap kekerasan dan struktur mikro paduan Aluminium 6061 maka dirancang spesimen berbentuk plat dengan sambungan las tumpul dengan kampuh $\mathrm{V}$ ganda hasil pengelasan Tungsten Inert Gas (TIG). Dalam penelitian ini variasi yang digunakan adalah kuat arus sebesar 100 A, 110 A dan 115 A.

\section{B. METODE}

Metode penelitian ini menggunakan metode eksperimen. Penelitian eksperimen yang dilaksanakan di leboratorium dengan kondisi dan peralatan yang diselesaikan guna memperoleh data untuk dikaji karakteristik fisik dan mekanik hasil hasil pengelasan paduan Aluminium 6061 menggunakan variasi kuat arus dengan metode las TIG. Bahan yang dipakai pada penelitian ini adalah plat paduan Aluminium 6061. Filler rod yang dipakai menggunakan ER 4043.

Pengujian yang dilakukan meliputi uji komposisi kimia, metalografi (struktur mikro), dan uji kekerasan. Alat yang digunakan dalam penelitian ini adalah mesin gerinda tangan, jangka sorong, mesin Spectrometer Metal Scan, mesin Olympus Metallurgical Microcope, mesin Micro Hardnes Tester Vickers. Spesimen yang digunakan pada penelitian ini berjumlah 4 buah, 3 hasil spesimen pengelasan dan 1 bahan tanpa las. Ukuran masing-masing spesimen $80 \mathrm{~mm}$ x $30 \mathrm{~mm}$ x 6,5 mm. Sambungan las menggunakan kampuh $\mathrm{V}$ ganda dan jenis pengelasan menggunakan pengelasan Gas Tungsten Arc Welding (GTAW). Sebelum melakukan uji kekerasan dan metalografi pada hasil pengelasan, terlebih dahulu dilakukan uji komposisi kimia untuk mengetahui unsur-unsur kimia yang ada pada paduan Aluminium 6061.

Teknik analisis data yang digunakan dalam penelitian ini adalah analisis dengan metode deskriptif komparatif. Data yang diperoleh dalam penelitian in berupa data komposisi kimia, kekerasan, dan struktur 
mikro serta dari observasi kemudian dianalisis secara deskriptif.

\section{HASIL DAN PEMBAHASAN}

Dalam pengujian komposisi kimia diketahui sebanyak tujuh belas unsur kimia yang terdapat pada paduan Aluminium 6061 sebagaimana terlihat pada Tabel 1.

Tabel 1. Hasil Uji Komposisi Kimia Paduan Aluminium 6061

\begin{tabular}{cccc}
\hline \multirow{2}{*}{ No } & \multirow{2}{*}{ Unsur } & \multicolumn{2}{c}{ Kandungan Berat (\%) } \\
\cline { 3 - 4 } & & Sebelum dilas & Las TIG \\
\hline 1 & $\mathrm{Al}$ & 95,08 & 96,61 \\
2 & $\mathrm{Si}$ & 0,867 & 0,430 \\
3 & $\mathrm{Fe}$ & 0,371 & 0,371 \\
4 & $\mathrm{Cu}$ & 0,161 & $p, 162$ \\
5 & $\mathrm{Mn}$ & $<0,0200$ & $<0,0200$ \\
6 & $\mathrm{Mg}$ & 1,15 & 0,900 \\
7 & $\mathrm{Cr}$ & 0,0288 & 0,0288 \\
8 & $\mathrm{Ni}$ & 0,0220 & 0,0230 \\
9 & $\mathrm{Zn}$ & 0,0429 & 0,0429 \\
10 & $\mathrm{Sn}$ & 0,0569 & 0,0569 \\
11 & $\mathrm{Ti}$ & 0,0182 & 0,0182 \\
12 & $\mathrm{~Pb}$ & $<0,0300$ & $<0,0300$ \\
13 & $\mathrm{Be}$ & 0,0005 & 0,0005 \\
14 & $\mathrm{Ca}$ & 0,0039 & 0,0041 \\
15 & $\mathrm{Sr}$ & $<0,0005$ & $<0,0005$ \\
16 & $\mathrm{~V}$ & $<0,0100$ & $<0,0100$ \\
17 & $\mathrm{Zr}$ & $<0,0030$ & $<0,0030$ \\
\hline
\end{tabular}

Data hasil uji komposisi kimia menunjukkan ada perbedaan yang tidak signifikan antara bahan paduan aluminium 6061 yang belum dilas dan setelah dilas, dengan persentase yang berbeda-beda pada setiap unsur kimia di dalam bahan paduan aluminium.

Berdasarkan hasil uji komposisi kimia pada Tabel 1 dapat diketahui bahwa unsur utama penyusun paduan aluminium 6061 sebelum dilas adalah Aluminium (Al) 95,08 \%, Magnesium (Mg) 1,15\%, Silicon (Si) $0,867 \%$, Iron $(\mathrm{Fe}) 0,371 \%$ dan $\mathrm{Cu}$
0,161 \%. Kemudian setelah dilakukan pengelasan dengan metode las TIG beberapa unsur mengalami perubahan jumlah kandungannya. Kandungan unsur Si mengalami penurunan menjadi $0,430 \%$ dari 0,867 \% dan unsur MG yang semula $1,15 \%$ menjadi $0,900 \%$. Perubahan beberapa unsur tersebut diduga berasal dari filler yang digunakan pada saat pengelasan, yaitu ER 4043 .

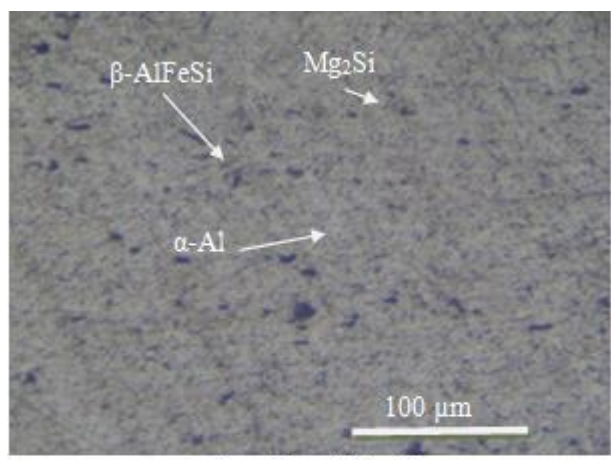

1. Base Material
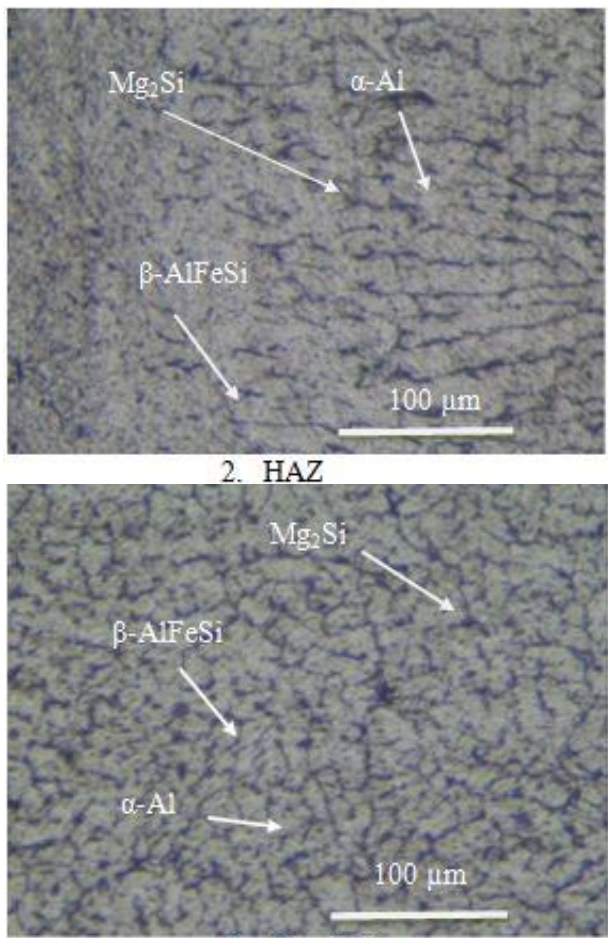

3. Daerah Las

Gambar 1. Hasil Uji Struktur Mikro spesimen paduan aluminium 6061, Arus 100 A, Perbesaran 100x 
Pengujian struktur mikro pada penelitian ini bertujuan untuk mengetahui struktur mikro baik pada spesimen uji sebelum dilakukan pengelasan maupun hasil pengelasan TIG.

Gambar 1 menunjukkan hasil uji struktur mikro pada base material, HAZ dan daerah las dengan kuat arus $100 \mathrm{~A}$. Pada base material fasa $\alpha$-Al cenderung menyebar secara merata pada seluruh bagian permukaan. Fasa tersebut terlihat rapat karena tidak adanya celah yang diisi oleh fasa $\mathrm{Mg}_{2} \mathrm{Si}$.

Pada HAZ menunjukkan adanya perubahan ukuran fasa $\alpha-\mathrm{Al}$. Fasa $\alpha-\mathrm{Al}$ yang semula rapat karena tidak adanya celah fasa $\mathrm{Mg}_{2} \mathrm{Si}$ berubah menjadi memanjang dan merenggang. Sedangkan fasa $\mathrm{Mg}_{2} \mathrm{Si}$ terlihat lebih dominan dari pada daerah base material yang menyebar di sela-sela fasa $\alpha$-Al.

Daerah las menunjukkan adanya perubahan ukuran fasa $\alpha-\mathrm{Al}$ yang semula panjang dan renggang pada daerah HAZ menjadi kecil dan banyak fasa $\mathrm{Mg}_{2} \mathrm{Si}$ yang mengelilingi setiap fasa $\alpha-\mathrm{Al}$.

Gambar 1 menunjukkan bahwa terjadi perubahan ukuran fasa $\alpha$-Al dan fasa $\mathrm{Mg}_{2} \mathrm{Si}$. Daerah yang mempunyai fasa $\mathrm{Mg}_{2} \mathrm{Si}$ paling banyak yaitu pada daerah las. Sedangkan yang paling sedikit pada daerah base material.
Dari ketiga daerah spesimen hasil las juga terdapat fasa $\beta$-AlFeSi. Fasa $\beta$-AlFeSi tersebut hanya nampak di beberapa tempat di semua daerah spesimen hasil las karena kecilnya presentase unsur Fe.

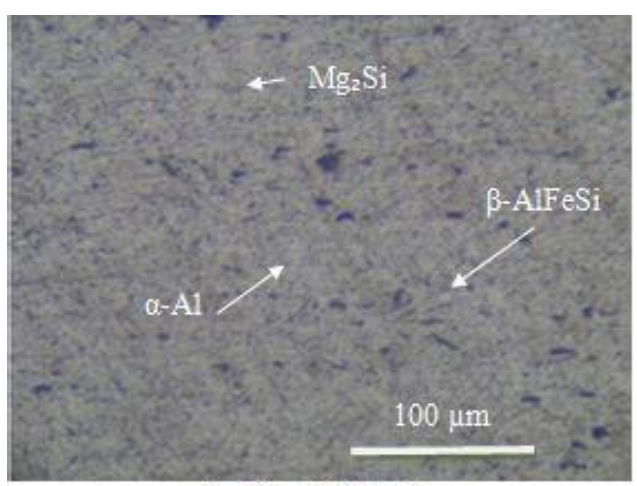

1. Base Material
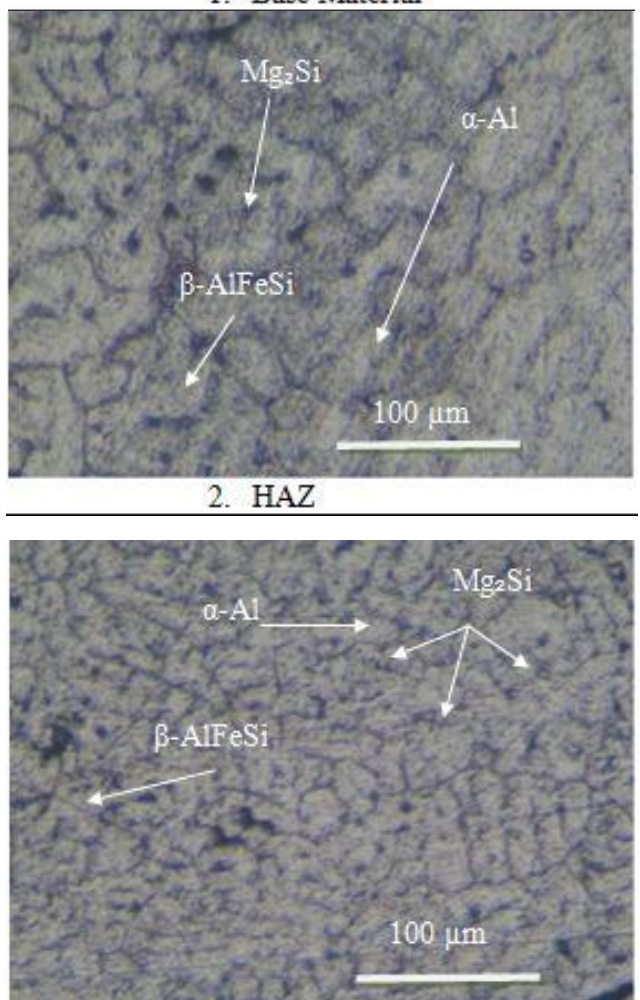

3. Daerah Las

Gambar 2. Hasil Uji Struktur Mikro spesimen paduan aluminium 6061, Arus 110 A, Perbesaran 100x

Gambar 2 menunjukkan hasil uji struktur mikro pada base material, HAZ dan daerah las dengan kuat arus $110 \mathrm{~A}$. 
Pada base material fasa $\alpha$-Al cenderung menyebar secara merata pada seluruh bagian permukaan. Fasa tersebut terlihat rapat karena tidak adanya celah yang diisi oleh fasa $\mathrm{Mg}_{2} \mathrm{Si}$.

HAZ menunjukkan adanya perubahan ukuran fasa $\alpha$-Al. Fasa $\alpha$-Al yang semula rapat karena tidak adanya celah fasa $\mathrm{Mg}_{2} \mathrm{Si}$ berubah menjadi gumpalan besar yang terpisah oleh fasa $\mathrm{Mg}_{2} \mathrm{Si}$. Berdasarkan gambar daerah HAZ arus $110 \mathrm{~A}$ dan $100 \mathrm{~A}$ diketahui bahwa fasa $\mathrm{Mg}_{2} \mathrm{Si}$ lebih dominan pada daerah HAZ arus $110 \mathrm{~A}$.

Daerah las menunjukkan adanya perubahan ukuran fasa $\alpha$-Al yang semula berbentuk gumpalan besar pada daerah $\mathrm{HAZ}$ menjadi kecil dan banyak fasa $\mathrm{Mg}_{2} \mathrm{Si}$ yang mengelilingi setiap fasa $\alpha$-Al. Pada daerah las arus $110 \mathrm{~A}$ dan $100 \mathrm{~A}$ dapat diketahui bahwa fasa $\mathrm{Mg}_{2} \mathrm{Si}$ terlihat lebih dominan pada daerah HAZ arus $110 \mathrm{~A}$.

Pada Gambar 2 terjadi perubahan ukuran fasa $\alpha-\mathrm{Al}$ dan fasa $\mathrm{Mg}_{2} \mathrm{Si}$. Daerah yang mempunyai fasa $\mathrm{Mg}_{2} \mathrm{Si}$ paling banyak yaitu pada daerah las. Sedangkan yang paling sedikit pada daerah base material.

Dari ketiga daerah spesimen hasil las terdapat fasa $\beta$-AlFeSi. Fasa $\beta$-AlFeSi tersebut hanya nampak di beberapa tempat di semua daerah spesimen hasil las karena kecilnya presentase unsur Fe.
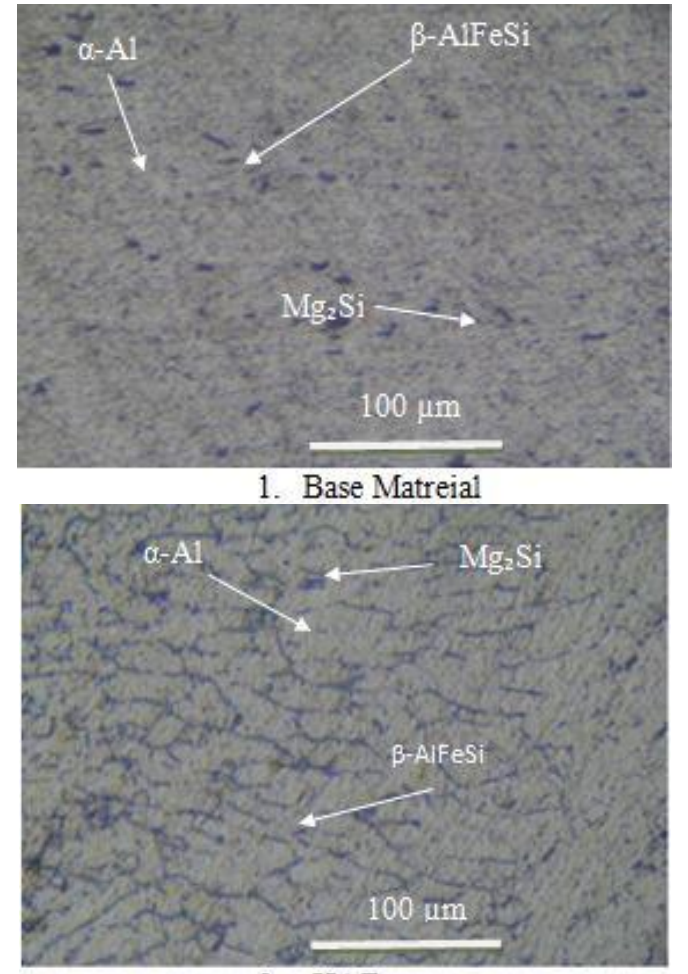

2. HAZ

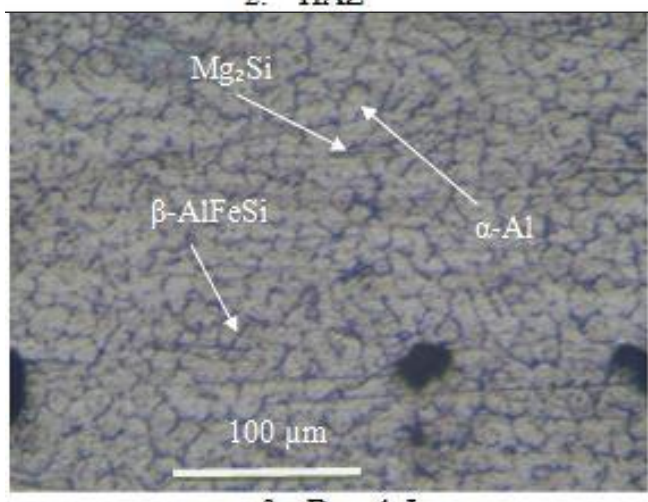

3. Daerah Las

Gambar 3 Hasil Uji Struktur Mikro spesimen paduan aluminium 6061, Arus 115 A, Perbesaran 100x

Gambar 3 menunjukkan hasil uji struktur mikro pada base material, HAZ dan daerah las dengan kuat arus $115 \mathrm{~A}$. Pada base material fasa $\alpha$-Al cenderung menyebar secara merata pada seluruh bagian permukaan. Fasa tersebut terlihat rapat karena tidak adanya celah yang diisi oleh fasa $\mathrm{Mg}_{2} \mathrm{Si}$. 
Pada HAZ menunjukkan adanya perubahan ukuran fasa $\alpha$-Al. Fasa $\alpha$-Al yang semula rapat karena tidak adanya celah fasa $\mathrm{Mg}_{2} \mathrm{Si}$ berubah menjadi memanjang dan merenggang. Akan tetapi jika dibandingkan pada HAZ arus $100 \mathrm{~A}$ ukuran fasa $\alpha$-Al lebih besar.

Daerah las menunjukkan adanya perubahan ukuran fasa $\alpha$-Al yang semula berbentuk memanjang dan merenggang pada daerah HAZ menjadi kecil dan banyak fasa $\mathrm{Mg}_{2} \mathrm{Si}$ yang mengelilingi setiap fasa $\alpha-\mathrm{Al}$.

Berdasarkan hasil pengujian struktur mikro pada kuat arus 100 A, 110 A dan 115 A terlihat bahwa daerah base material cenderung sama. Pada HAZ menunjukkan bahwa fasa $\mathrm{Mg}_{2} \mathrm{Si}$ yang paling dominan yaitu HAZ dengan kuat arus 110 A. Sedangkan pada daerah las fasa $\mathrm{Mg}_{2} \mathrm{Si}$ yang paling dominan hasil lasan dengan kuat arus 110 A. Semakin banyak fasa $\mathrm{Mg}_{2} \mathrm{Si}$ maka akan meningkatkan kekuatan dan kekerasan logam tersebut (Setyawan: 2014). Berdasarkan penelitian tersebut, maka daerah yang memiliki nilai kekerasan tertinggi terdapat pada hasil las dengan kuat arus $110 \mathrm{~A}$.

Pengujian kekerasan dilakukan pada spesimen tanpa las dan juga hasil pengelasan yang meliputi daerah las, HAZ (Heat Affection Zone) dan pada base material. Diagonal hasil injakan indentor kerucut intan diukur dengan bantuan lensa pembesar (Linen Tester Lope).

Berdasarkan hasil pengamatan dari pengujian kekerasan Vickers, nilai kekerasan tertinggi terdapat pada spesimen hasil las dengan kuat arus 110 A yaitu 65,4 VHN. Sedangkan pada spesimen hasil las dengan kuat arus 100 A dan 115 A hanya sebesar 55,7 VHN dan 55,9 VHN. Daerah las pada ketiga spesimen cenderung lebih keras jika dibandingkan dengan HAZ dan base material. Jika diamati pada struktur mikronya, daerah las cenderung memiliki area batas butir yang luas. Peningkatan kekerasan dipengaruhi banyaknya kandungan senyawa $\mathrm{Mg}_{2} \mathrm{Si}$, dimana $\mathrm{Mg}_{2} \mathrm{Si}$ terbentuk adanya kombinasi antara magnesium dengan silikon. Persebaran $\mathrm{Mg}_{2} \mathrm{Si}$ pada daerah las terlihat merata jika dibandingkan dengan daerah HAZ dan base material.

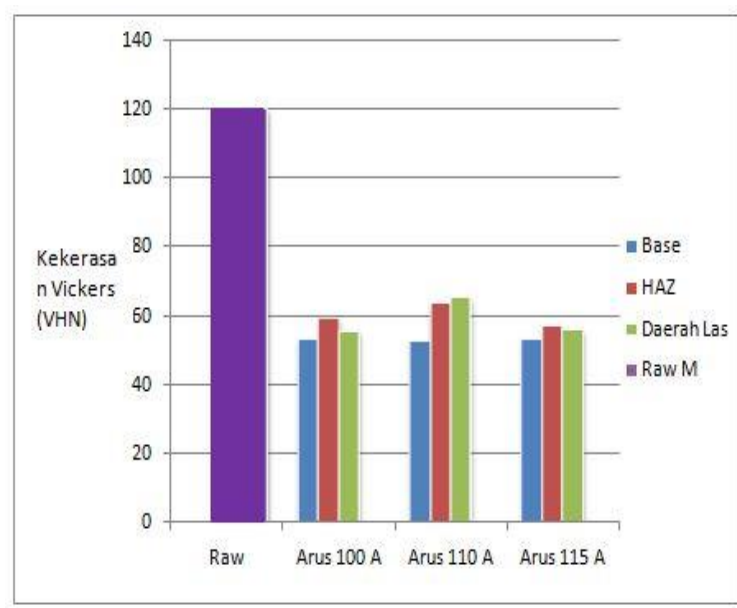

Gambar 4. Nilai Rata-rata Uji Kekerasan Vickers 
Gambar 4 menunjukkan hasil uji kekerasan spesimen tanpa las (raw material) dengan nilai kekerasan sebesar 120,4 VHN.

Dibandingkan dengan ketiga spesimen hasil pengelasan menggunakan kuat arus berbeda, tingkat kekerasan pada raw material cenderung lebih tinggi. Menurunnya nilai kekerasan pada spesimen hasil pengelasan dikarenakan adanya perubahan struktur mikro, yaitu menurunnya kandungan unsur $\mathrm{Mg}_{2} \mathrm{Si}$, terlihat lebih sedikit, dan penyebaran yang tidak merata pada permukaan unsur $\alpha-\mathrm{Al}$.

\section{PENUTUP}

Berdasarkan hasil penelitian maka dapat ditarik kesimpulan sebagai berikut :

1. Terdapat pengaruh kuat arus terhadap struktur mikro hasil pengelasan paduan aluminium 6061 dengan kuat arus $100 \mathrm{~A}, 110 \mathrm{~A}$ dan $115 \mathrm{~A}$ Struktur mikro pada base material setiap spesimen cenderung hampir sama. Pada HAZ menunjukkan bahwa fasa $\mathrm{Mg}_{2} \mathrm{Si}$ yang paling dominan yaitu HAZ dengan kuat arus 110 A. Sedangkan pada daerah las fasa $\mathrm{Mg}_{2} \mathrm{Si}$ yang paling dominan hasil lasan dengan kuat arus $110 \mathrm{~A}$.

2. Terdapat pengaruh kuat arus terhadap tingkat kekerasan hasil pengelasan paduan aluminium 6061 dengan kuat arus $100 \mathrm{~A}, 110 \mathrm{~A}$ dan $115 \mathrm{~A}$. Spesimen dengan kuat arus 110 A mempunyai tingkat kekerasan yang lebih tinggi yaitu 65,4 VHN jika dibandingkan dengan spesimen kuat arus 100 A sebesar 55,7 VHN dan 115 A sebesar 55,9 VHN. Hasil uji kekerasan spesimen tanpa las (raw material) sebesar 120,4 VHN. Nilai kekerasan pada raw material cukup tinggi jika dibandingkan dengan nilai kekerasan ketiga spesimen yang dilas dengan variasi arus berbeda, dengan demikian spesimen hasil pengelasan tidak mampu mengembalikan nilai kekerasan pada spesimen paduan Aluminium 6061 sebelum dilakukan proses pengelasan

\section{DAFTAR PUSTAKA}

ASM Handbook. 1992. Volume 9: Metalography and Microstructure. United State of America.

Dadang. 2013. Teknik Las GTAW 1. Jakarta: Kementerian Pendidikan dan Kebudayaan

Khudadad, M. A. R. (2014). Corrosion Resistance of TIG Welding Joint for Aluminium Alloy 6061- T6 in Sea Water at Different Velocities. Journal of Engineering and Development, Vol. 18, No.6, November 2014, ISSN 1813- 7822 . 
Sholichudin, M. (2015). Perbedaan Sifat Mekanik Hasil Penyambungan Las GTAW pada Aluminium 6061 dengan Filler ER 4043 dan ER 5356. Surabaya: D3 Teknik Mesin, Fakultas Teknologi Industri, ITS.
Yoedhawan, A. J. P. (2014). Jurnal ROTOR Volume 7 Nomor 2. Jember: Jurusan Teknik Mesin Fakultas Teknik Universitas Jember. 